Preprints of the

Max Planck Institute for

Research on Collective Goods

Bonn 2007/6

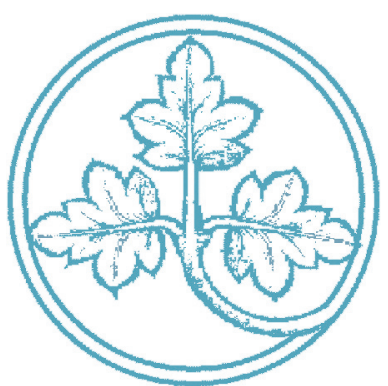

Incentives for Process

Innovation in a

Collusive Duopoly

Christoph Engel

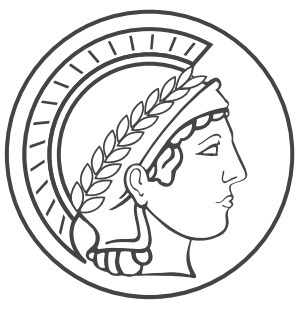




\section{Incentives for Process Innovation in a Collusive Duopoly}

Christoph Engel

May 2007 


\begin{abstract}
Two suppliers of a homogenous good know that, in the second period, they will be able to collude. Gains from collusion are split according to the Nash bargaining solution. In the first period, either of them is able to invest into process innovation. Innovation changes the status quo payoff, and thereby affects the distribution of the gains from collusion. The resulting innovation incentive is strictly smaller than in the competitive
\end{abstract} case.

JEL: D43, K21, L13, O31

Keywords: Duopoly, Collusion, Innovation Incentives

SSRN: ERN: IO Theory; IO Regulation, Antitrust \& Privatization; Max Planck

LSN: Antitrust Law \& Policy 


\title{
Incentives for Process Innovation in a Collusive Duopoly
}

\author{
Christoph Engel \\ Max-Planck-Institute for Research on Collective Goods \\ Kurt-Schumacher-Straße 10 \\ D 53113 Bonn \\ $++49 / 228 / 9141610$ \\ engel@coll.mpg.de \\ Helpful comments by Martin Hellwig, Philip Weinschenk \\ and Andreas Nicklisch on an earlier version \\ are gratefully acknowledged.
}

May 1, 2007

\section{Introduction}

Is competition good for innovation? There is a large literature comparing monopoly and competition, going back to [Schumpeter 1912] [Arrow 1962]. This paper adds the comparison between collusion and competition. It introduces a two-period model. Two suppliers of a homogenous good know that, in the second period, they will be able to collude in the product market. However, in the first period, either of them is able to invest into process innovation. Collusion in the first period is excluded.

The paper shows that collusion does leave room for innovation. The innovation incentive is due to the fact that the distribution of gains from collusion is at stake. The paper assumes that cartel profits are shared in accordance with the Nash bargaining solution, with status quo payoffs given by the players payoffs in the noncooperative version of the price setting game. If only one firm innovates, this changes the status quo payoff to the advantage of the innovator and to the disadvantage of the competitor. The competitor loses part of the gains from collusion. Innovation is no longer driven by greed only. The complementary motive of fear comes into play. Yet in the collusive case, innovation incentives are weaker than in the competitive case. In the competitive case, the innovator undercuts the previous competitive price. It sells the previous competitive 
quantity $+\varepsilon$, but produces at the lower cost. This gives the innovator a positive profit. It is the quantity sold, times the cost reduction $-\varepsilon$.

Moreover, without collusion, in equilibrium only one firm innovates, provided the cost of innovation is smaller than the profit of the innovator. If both innovate, both make zero profit, and have to bear the cost of innovation. If the other firm innovates, it is the best response not to engage in innovation. This result also holds with collusion if innovation is so costly that it is only profitable for a single innovator. However, if innovation is less costly, in equilibrium both firms innovate. This even holds if, as a result, both of them are worse off than before innovation. This is an equilibrium as long as not being the innovator reduces the profit even more.

It seems that the question has not been investigated thus far. Closest is [Arrow 1962]. But in his paper, competition is compared to monopoly, not to collusion. Moreover there is intellectual property, which is assumed away here. Most of the large literature on innovation has assumed competition in the product markets [Freeman 1960, for an overview]. This is different for the literature on R\&D joint ventures [d'Aspremont 1988] [Cellini 2002] [Suetens 2005]. However, these authors are interested in cooperative or collusive invention, not in collusion in the product markets. There is an extensive literature on differentiated oligopoly [Cellini 2003, for an overview]. Most of this literature is interested in the effects of innovation on the stability of explicit or implicit cartels [Deneckere 1983] [Wernerfeld 1986] [Rothschild 1992] [Ross 1992] [Raith 1996] [Rothschild 1997] [Albaek 1998] [Lambertini 1999] [Posada 2000] [Symeonidis 2002]. Others wanted to know how firms self-select to different points of the quality spectrum [Dutta 1990] [Lambertini 1996], and what the prospect of future competition means for innovation investment [Lambertini 1998]. Yet others have investigated under which conditions collusion in sequential innovation might be socially beneficial [Denicolò 2002].

The paper is organised as follows. Section 2 introduces the model. Section 3 compares the incentives for process innovation in the competitive and in the collusive case. Section 4 discusses the robustness of the results. Section 5 concludes.

\section{The Model}

Two risk-neutral firms play a game in two periods. In the first period, they have an opportunity to do research and development regarding the technology to produce a homogenous good. In the second period, they compete in price. In the product market, they interact simultaneously. For the demand, switching from one supplier to another is free of charge. Production is to demand. Demand is given by $p=\alpha-\beta Q$, where $p$ is price, $Q$ is quantity, $\alpha$ is the intercept, and $\beta$ is the slope. Demand takes the prices posted by the suppliers.

The firms are able to collude in the product market. They split gains from collusion according to the Nash bargaining solution [Nash 1950]. Each firm is 
able to enforce the collusion agreement against the other. Side payments are possible and enforceable.

Initially both suppliers have identical constant marginal production cost $\rho<$ $\alpha$. There is no fixed cost. In the first period, they have the costly opportunity to invest in process innovation. It reduces production cost to $\rho-\sigma<\alpha$. Innovation cost $I$ is common knowledge. If innovation has been successful, each supplier may credibly inform its competitor about the resulting reduction in production cost.

The resulting two period game is solved by backwards induction. The firms anticipate their payoffs in four situations: neither of them invests $\Pi_{00}$, the other invests $\Pi_{01}$, both invest $\Pi_{11}$, the firm is the only to invest $\Pi_{10}$. Based on these results, and on $I$, they decide whether to invest.

\section{Innovation Incentives}

Innovation incentives in the noncooperative case provide the benchmark. They result from comparing payoffs pre and post innovation. In the collusive case, the payoff pre innovation is half the gains from collusion. Innovation increases the gains from collusion, and it gives the innovator a higher status quo payoff. These effects translate into a higher payoff for the innovator, and a lower payoff for the competitor, compared to the gains from collusion pre innovation. If both innovate, they split the increased gains from collusion evenly. Consequently, a firm is best off if it is the only to innovate, over being one of two innovators, over both not innovating, over being the one that has not innovated, if the other has innovated. Given this ranking of payoffs, innovation incentives are driven by innovation cost. It turns out that innovation incentives are always stronger in the competitive case, and that collusion is never efficient.

\subsection{The Competitive Benchmark}

If there is no collusion in the second period, the firms play the standard Bertrand game with price $p^{*}=\rho$, and industry quantity $Q^{*}=\frac{\alpha-\rho}{\beta}$. This gives each of them $\Pi_{00}^{*}=0$. If both innovate, they still expect $\Pi_{11}^{*}=0$. If only one of them innovates, it has

$$
\Pi_{10}^{*}=\sigma\left(\frac{\alpha-\rho}{\beta}\right)
$$

The incumbent has $\Pi_{01}^{*}=0$. Payoffs are thus ranked $\Pi_{10}^{*}>\Pi_{11}^{*}=\Pi_{00}^{*}=\Pi_{01}^{*}$. It is straightforward to see that, in pure strategies, one and only one firm invests if $\Pi_{10}^{*}-I>0$. Consequently, for innovation to occur, the innovation cost may at most be

$$
I_{\max }^{*}<\sigma\left(\frac{\alpha-\rho}{\beta}\right)
$$

Otherwise, there is no investment. 


\subsection{Collusion Without Innovation}

If they collude, the two firms set cartel price $p^{C}=\frac{\alpha+\rho}{2}$ and sell $Q^{C}=\frac{\alpha-\rho}{2 \beta}$. Industry profit is

$$
\Pi^{C}=\frac{(\alpha-\rho)^{2}}{4 \beta}
$$

The Nash bargaining scheme asks them to split this evenly, so that each of them has

$$
\Pi_{00}=\frac{(\alpha-\rho)^{2}}{8 \beta}
$$

\subsection{Innovation}

If only one firm innovates, its status quo payoff goes up to

$$
\Pi_{10}^{*}=\sigma\left(\frac{\alpha-\rho}{\beta}\right)
$$

while the status quo payoff of the incumbent remains $\Pi_{01}^{*}=0$. The new profit maximising price and quantity are

$$
\begin{aligned}
& \hat{p}^{C}=\frac{\alpha+\rho-\sigma}{2} \\
& \hat{Q}^{C}=\frac{\alpha-\rho+\sigma}{2 \beta}
\end{aligned}
$$

If the innovation is radical, i.e. if

$$
\hat{p}^{C}=\frac{\alpha+\rho-\sigma}{2}<\rho
$$

there is no longer room for collusion. However, if

$$
\sigma \leq \alpha-\rho
$$

, i.e. if the innovation is non-radical, the competitor is still able to undercut the profit maximising price. In a cartel, the competitor agrees not to supply the product, against a side payment. Industry profit then is

$$
\hat{\Pi}^{C}=\frac{(\alpha-\rho+\sigma)^{2}}{4 \beta}
$$

The Nash bargaining scheme requires

$$
\max _{x}\left(x-\Pi_{10}^{*}\right)\left(\hat{\Pi}^{C}-x-\Pi_{01}^{*}\right)
$$

and gives the innovator

$$
\Pi_{10}=\frac{\hat{\Pi}^{C}+\Pi_{10}^{*}}{2}=\frac{(\alpha+\sigma-\rho)^{2}}{8 \beta}+\frac{\sigma(\alpha-\rho)}{2 \beta}
$$


and the incumbent

$$
\Pi_{01}=\frac{\hat{\Pi}^{C}-\Pi_{10}^{*}}{2}=\frac{(\alpha+\sigma-\rho)^{2}}{8 \beta}-\frac{\sigma(\alpha-\rho)}{2 \beta}
$$

If both firms innovate, their status quo payoffs go down to 0 . The Nash bargaining solution splits $\hat{\Pi}^{C}$ evenly. Each then has

$$
\Pi_{11}=\frac{(\alpha+\sigma-\rho)^{2}}{8 \beta}
$$

\subsection{Ranking of Payoffs}

Proposition 1 If the innovation is non radical in the sense of (1), payoffs are ranked $\Pi_{10}>\Pi_{11}>\Pi_{00}>\Pi_{01}$.

To see this, compare them piecewise.

$$
\Pi_{10}-\Pi_{11}=\frac{\sigma(\alpha-\rho)}{2 \beta}
$$

is positive since $\alpha>\rho . \Pi_{11}>\Pi_{00}$ is straightforward since $\sigma>0 . \Pi_{00}>\Pi_{01}$ requires

$$
\Pi_{00}-\Pi_{01}=\frac{\sigma(2 \alpha-2 \rho-\sigma)}{8 \beta}>0
$$

If the innovation is non-radical, $2 \alpha-2 \rho-\sigma \geq \alpha-\rho>0$. Hence the inequality holds.

This is not surprising. At the borderline, i.e. with $\sigma=\alpha-\rho$, the innovator is indifferent between collusion and going it alone, since the Nash bargaining scheme gives the competitor a payoff of 0 .

$$
\left.\Pi_{01}\right|_{\sigma=\alpha-\rho}=\frac{(\alpha+(\alpha-\rho)-\rho)^{2}}{8 \beta}-\frac{(\alpha-\rho)(\alpha-\rho)}{2 \beta}=0
$$

Were they still to calculate the same way, with $\sigma=\alpha-\rho+\varepsilon$, the Nash result for the competitor would grow to

$$
\frac{\varepsilon^{2}}{8 \beta}
$$

However this is meaningless since the Nash bargaining solution only makes sense if there are gains from trade. 


\subsection{The Innovation Game}

To analyse innovation decisions, consider the following matrix:

$$
\begin{array}{ccc} 
& \text { innovate } & \text { no } \\
\text { innovate } & \Pi_{11}, \Pi_{11} & \Pi_{10}, \Pi_{01} \\
\text { no } & \Pi_{01}, \Pi_{10} & \Pi_{00}, \Pi_{00}
\end{array}
$$

Both firms innovate if $\Pi_{10}-I>\Pi_{11}-I>\Pi_{00}>\Pi_{01}$, and if $\Pi_{10}-I>\Pi_{00}>$ $\Pi_{11}-I>\Pi_{01}$. The latter case is possible only because, ignoring investment cost, $\Pi_{00}>\Pi_{01}$. Note that in this case both firms lose money, compared to the situation without innovation. In this case, the Bertrand dilemma extends to the two period game with innovation. Finally, double investment is a possibility if $\Pi_{00}>\Pi_{10}-I>\Pi_{11}-I>\Pi_{01}$. In the one equilibrium in pure strategies, both firms invest. In the other both do not invest. In the latter, their payoffs are higher. One firm innovates if $\Pi_{10}-I>\Pi_{00}>\Pi_{01}>\Pi_{11}-I$. No firm innovates if $\Pi_{00}>\Pi_{01}>\Pi_{10}-I>\Pi_{11}-I$ and if $\Pi_{00}>\Pi_{10}-I>\Pi_{01}>\Pi_{11}-I$.

The maximum investment cost $I$ depends on the equilibrium. If in equilibrium only one firm innovates,

$$
\Pi_{10}-I>\Pi_{00} \Rightarrow I_{\max }^{C}<\Pi_{10}-\Pi_{00}=\frac{1}{8} \frac{\sigma}{\beta}(6 \alpha+\sigma-6 \rho)
$$

must hold. If $\Pi_{00}>\Pi_{10}-I>\Pi_{11}-I>\Pi_{01}$, and if $\Pi_{10}-I>\Pi_{00}>\Pi_{11}-I>$ $\Pi_{01}$

$$
\Pi_{11}-I>\Pi_{01} \Rightarrow I_{\text {intermediate }}^{C}<\Pi_{11}-\Pi_{01}=\frac{1}{2} \frac{\sigma}{\beta}(\alpha-\rho)
$$

must hold. Finally, in the first game,

$$
\Pi_{11}-I>\Pi_{00} \Rightarrow I_{\min }^{C}<\Pi_{11}-\Pi_{00}=\frac{1}{8} \frac{\sigma}{\beta}(2 \alpha+\sigma-2 \rho)
$$

To see how the respective maximum investments are ranked, check

$$
I_{\max }^{C}-I_{\text {intermediate }}^{C}=\frac{1}{8} \frac{\sigma}{\beta}(2 \alpha+\sigma-2 \rho)
$$

This is positive since, from the assumptions, $\alpha>\rho$.

$$
I_{\text {intermediate }}^{C}-I_{\min }^{C}=\frac{1}{8} \frac{\sigma}{\beta}(2 \alpha-\sigma-2 \rho)
$$

From (1), $\sigma \leq \alpha-\rho$. Evaluating $I_{\text {intermediate }}^{C}-I_{\min }^{C}$ at the borderline yields $\frac{1}{8 \beta}(\alpha-\rho)^{2}$. However large $\sigma$, the difference thus is positive. 


\subsection{Welfare Assessment}

In the competitive case, consumer rent is given by

$$
R^{*}=\frac{(\alpha-\rho)^{2}}{2 \beta}
$$

Provided there is investment, welfare is

$$
W^{*}=(\alpha-\rho+\sigma) \frac{\alpha-\rho}{\beta}-I
$$

Without innovation, but with collusion, consumer rent is

$$
R_{00}=\frac{\left(\alpha-p^{C}\right) Q^{C}}{2}=\frac{(\alpha-\rho)^{2}}{8 \beta}
$$

Welfare is given by

$$
W_{00}=R_{00}+\Pi^{C}=\frac{3(\alpha-\rho)^{2}}{8 \beta}
$$

If either or both firms innovate, consumer rent goes up to

$$
R_{10}=R_{11}=\frac{(\alpha-\rho+\sigma)^{2}}{8 \beta}
$$

If only one firm innovates, welfare is

$$
W_{10}=R_{10}+\hat{\Pi}^{C}-I=\frac{3(\alpha-\rho+\sigma)^{2}}{8 \beta}-I
$$

If both firms innovate, welfare is reduced to

$$
W_{11}=\frac{3(\alpha-\rho+\sigma)^{2}}{8 \beta}-2 I
$$

Hence it is never efficient that both firms innovate.

Proposition 2 The maximum investment is larger in the competitive than in the collusive case.

In the competitive case, never both firms innovate. One firm innovates if

$$
I_{\max }^{*}<\frac{\sigma(\alpha-\rho)}{\beta}
$$

In the collusive case, one firm innovates if

$$
I_{\max }^{C}<\frac{1}{8} \frac{\sigma}{\beta}(6 \alpha+\sigma-6 \rho)
$$




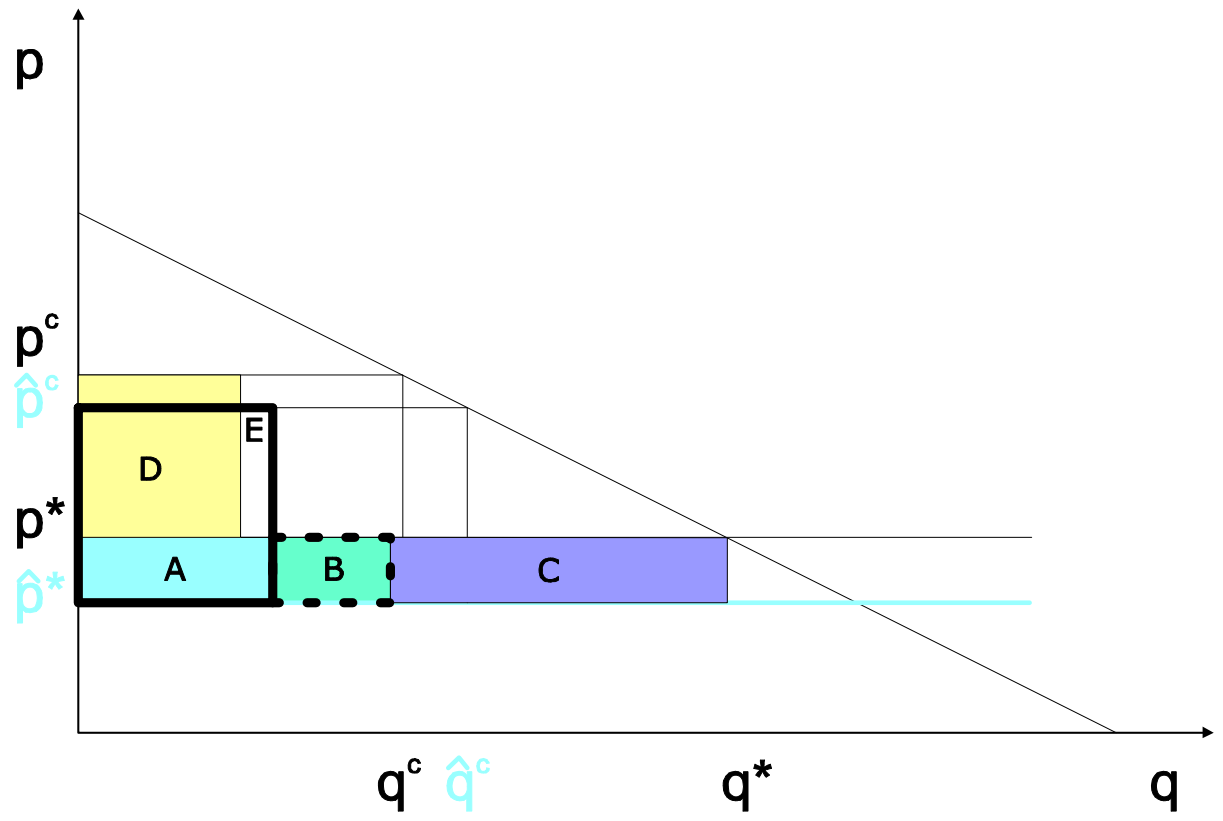

Figure 1: Comparing Innovation Incentives

Comparing one has

$$
I_{\max }^{*}-I_{\max }^{C}=\frac{1}{8} \frac{\sigma}{\beta}(2 \alpha-2 \rho-\sigma)
$$

Using (1), with the largest possible $\sigma$, this becomes $\frac{1}{8 \beta}(\alpha-\rho)^{2}$, which is positive. The maximum investment is larger in the competitive than in the collusive case.

Why is that? Collusion brings the innovator under the spell of its competitor. As long as the innovation is not radical, the innovator must give the competitor something in recompense for not using its power to undercut the new monopoly price. Of course, post innovation, Nash bargaining gives the innovator half of the status quo payoff plus half of the gains from collusion. With collusion, the innovator thus has a higher payoff than with competition. However, this is not how the innovator calculates. It compares innovating with not innovating, but colluding. In the latter case, its payoff would have been half of the gains from collusion without innovation. As long as the innovation is not radical, the innovator is unable to fully appropriate this. Graphically, the situation looks as in Figure 1.

In the competitive case, the innovator has $A+B+C$. With collusion, but without innovation, both firms have half the gains from collusion, or $D$. Post innovation, the innovator has half its status quo payoff, plus half the new gains from collusion, or $C+E . I_{\max }^{*}>I_{\max }^{C}$ holds if $A+B+C>C+E-D$, or if 
$A+B>E-D . E-D<A$ must hold. $p^{C}-\hat{p}^{C}<\sigma$. Innovation never lowers the cartel price as much as the innovation. Hence $I_{\max }^{*}-I_{\max }^{C}>B$.

Another way of making the point is this: The innovation incentive with competition enters Nash bargaining as the status quo payoff of the innovator. The Nash scheme gives the innovator half of this, plus half of the gains from collusion. From the latter, the innovator subtracts half of the gains from collusion pre innovation. Hence for innovation incentives to be stronger with collusion,

$$
\frac{1}{2} \hat{\Pi}^{C}-\frac{1}{2} \Pi^{C}>\frac{1}{2} \Pi_{10}^{*}=\Delta \Pi^{C}>\Pi_{10}^{*}
$$

would have to hold. However, the cartel sets $\hat{p}^{C}$ such that $\hat{p}^{C}-p^{C}<\sigma$. Moreover, since $\hat{p}^{C}>p^{*}$, the cartel only sells $\hat{Q}^{C}<Q^{*}$. Consequently in both the price and the quantity dimensions

$$
\Delta \Pi^{C}=\left(\hat{p}^{C}-p^{C}\right) \hat{Q}^{C}<\Pi_{10}^{*}=\sigma Q^{*}
$$

Using the respective maximum investment for assessing welfare, one has

$$
\begin{gathered}
W^{*}=(\alpha-\rho+\sigma) \frac{\alpha-\rho}{\beta}-\frac{\sigma(\alpha-\rho)}{\beta}=\frac{1}{\beta}(\alpha-\rho)^{2} \\
W_{10}^{C}=\frac{3(\alpha-\rho+\sigma)^{2}}{8 \beta}-\frac{1}{8} \frac{\sigma}{\beta}(6 \alpha+\sigma-6 \rho)=\frac{1}{8} \frac{\sigma}{\beta}(6 \alpha+\sigma-6 \rho)
\end{gathered}
$$

Comparing yields

$$
W^{*}-W_{10}^{C}=\frac{1}{8 \beta}\left(5 \alpha^{2}-10 \alpha \rho-2 \sigma^{2}+5 \rho^{2}\right)
$$

Using (1), and evaluating at the borderline, this becomes $3(\alpha-\rho)^{2}$, which is positive. Consequently, even if only one firm innovates, collusion is inefficient. The inefficiency grows if, in equilibrium, both firms innovate.

\section{Discussion}

How robust is the finding that innovation incentives are stronger with competition? Does the result only hold since marginal cost has been assumed to be constant? With decreasing marginal cost, the situation is pretty much the same. If they compete in the product market, and without innovation, both firms make zero profit. The same holds if both innovate. Hence in the competitive case, payoffs are ranked as with constant marginal cost. In equilibrium, only one firm innovates. With increasing marginal cost, there is a positive producer rent even without innovation or collusion. Innovation is no longer the only way to make a profit. This reduces innovation incentives if one compares constant and increasing marginal cost. However in the comparison between competition and collusion, given marginal cost increases, the opportunity cost resulting from the 
positive producer rent cancels out. For now both firms have a positive status quo payoff. The Nash solution gives the innovator half of the gains from collusion post innovation + half of its own status quo payoff - half of the status quo payoff of its competitor. Hence, the Nash result for the innovator is half of the increase in gains from collusion + half of the innovation incentive in the competitive case. For the same reason as with constant marginal cost, the increase in gains from collusion is strictly smaller than the innovation incentive in the competitive case.

\section{Conclusion}

The paper has two tentative messages, one to the intellectual property community, and another to the antitrust community. If firms compete in price, i.e. if capacity limits do not matter, intellectual property is not the only way how to incentivize innovation. A complementary incentive results from the desire to free oneself from control by the competitor. The effect remains strong if firms are able to collude in the product market, but it is strictly smaller than in the competitive case. This finding is particularly relevant in industries where the cost of inventing around is small, despite the existence of intellectual property rights [Levin 1987, 809, for empirical evidence].

The antitrust message is clear within the framework of the model presented in the paper. While collusion does only mildly affect innovation incentives, it is not efficient. A particularly harmful effect of collusion is that it induces double innovation whenever the innovation cost is sufficiently small.The antitrust message becomes more ambigous if one assumes a less certain world; innovation is about navigating uncharted territory, after all. Innovators hardly ever know exactly how likely they are to succeed. Normally, they do not even know ex ante what exactly success means. In innovative activities, the problem space is usually not well defined. In either case, double investment reduces the risk that there is no innovation at all since coordination on the equilibrium fails. It doubles the chances that a fundamental, rather than only a marginal innovation takes place. The fact that double investment does not yield zero profits works like an insurance. Even if the competitor also succeeds, innovation investments are not futile. Of course, the Harberger inefficiency persists, as do the X-inefficiencies that usually go along with cartels. But knowing about the positive effect on innovation incentives, antitrust policy faces a harder choice than is traditionally maintained.

\section{References}

Albaek, Svend and Luca Lambertini (1998). "Collusion in Differentiated Duopolies Revisited." Economics Letters 59: 305-308.

Arrow, Kenneth Joseph (1962). Economic Welfare and the Allocation of Resources for Invention. The Rate and Direction of Inventive Activity. Economic 
and Social Factors. Richard R. Nelson. Princeton, Princeton University Press: 609-630.

Cellini, Roberto and Luca Lambertini (1998). "A Dynamic Model of Differentiated Oligopoly with Capital Accumulation." Journal of Economic Theory 83: $145-155$.

Cellini, Roberto and Luca Lambertini (2002). "A Differential Game Approach to Investment in Product Differentiation." Journal of Economic Dynamics and Control 27: 51-62.

Cellini, Roberto and Luca Lambertini (2003). Differential Oligopoly Games. Technology, Information and Market Dynamics: Topics in Advanced Industrial Organization. Patrizio Bianchi und Luca Lambertini. Cheltenham, Elgar: 173207.

d'Aspremont, Claude and Alexis Jacquemin (1988). "Cooperative and Noncooperative R\&D in Duopoly with Spillovers." American Economic Review 78: 1133-1137.

Deneckere, Raymond J. (1983). "Duopoly Supergames with Product Differentiation." Economics Letters 11: 37-42.

Denicolò, Vincenzo (2002). "Sequential Innovation and the Patent-Antitrust Conflict." Oxford Economic Papers 54: 649-668.

Dutta, Prajit K., Saul Lach and Aldo Rustichini (1990). Innovation and Product Differentiation http://ideas.repec.org/p/fth/coluec/484.html.

Freeman, Christopher (1990). The Economics of Innovation. Cheltenham, Elgar.

Kamien, Morton I., Eitan Muller and Israel Zang (1992). "Research Joint Ventures and R\&D Cartels." American Economic Review 82: 1293-1306.

Lambertini, Luca (1996). "Choosing Roles in a Duopoly for Endogenously Differentiated Products." Australian Economic Papers 35: 205-224.

Lambertini, Luca and Gianpaolo Rossini (1998). "Product Heterogeneity as a Prisoner's Dilemma in a Duopoly with R\&D." Economics Letters 58: 297-301.

Lambertini, Luca and Dan Sasaki (1999). "Optimal Punishment in Linear Duopoly Supergames with Product Differentiation." Journal of Economics 69: 173-188.

Levin, Richard C., Alvin K. Klevorick, Richard R. Nelson, Sidney G. Winter, Richard Gilbert and Zvi Griliches (1987). "Appropriating the Returns from Industrial Research and Development." Brookings Papers on Economic Activity: 783-831.

Majerus, David W. (1988). "Price vs. Quantity Competition in Oligopoly Supergames." Economics Letters 27: 293-297.

Nash, John (1950). "The Bargaining Problem." Econometrica 18: 155-162.

Posada, Pedro (2000). Cartel Stability and Product Differentiation. How Much Do the Size of the Cartel and the Size of the Industry Matter?

http://ideas.repec.org/p/fth/warwec/556.html.

Raith, Michael A. (1996). Product Differentiation, Uncertainty and the Stability of Collusion http://ideas.repec.org/p/cep/stieip/16.html.

Ross, Thomas (1992). "Cartel Stability and Product Differentiation." International Journal of Industrial Organization 10: 1-13. 
Rothschild, Robert (1992). "On the Sustainability of Collusion in Differentiated Duopolies." Economics Letters 40: 33-37.

Rothschild, Robert (1997). "Product Differentiation and Cartel Stability. Chamberlin versus Hotelling." Annals of Regional Science 31: 259-271.

Schumpeter, Joseph Alois (1912). Theorie der wirtschaftlichen Entwicklung. Leipzig, Duncker \& Humblot.

Singh, Nirvikar and Xavier Vives (1984). "Price and Quantity Competition in a Differentiated Oligopoly." Rand Journal of Economics 15: 546-554.

Suetens, Sigrid (2005). "Cooperative and Noncooperative R\&D in Experimental Duopoly Markets." International Journal of Industrial Organization 23: 63-82.

Symeonidis, George (2002). "Cartel Stability with Multiproduct Firms." International Journal of Industrial Organization 20: 339-352.

Vilasuso, Jon and Mark R. Frascatore (2000). "Public Policy and R\&D When Research Joint Ventures are Costly." Canadian Journal of Economics 33: 818-839.

Wernerfelt, Birger (1986). Tacit Collusion and Product Differentiation http://ideas.repec.org/p/nwu/cmsems/693.html. 